\title{
O PRINCÍPIO DA PRECAUÇÃO SOB A PERSPECTIVA DA JUDICIALIZAÇÃO DOS DIREITOS FUNDAMENTAIS: RISCOS DO ATIVISMO JUDICIAL PARA A HARMONIA ENTRE PODERES.
}

\author{
Narciso Ferreira de Menezes ${ }^{1}$ \\ André Studart Leitão ${ }^{2}$
}

\section{RESUMO}

O presente estudo propõe-se a analisar as medidas e os limites de precaução adotados pelos Poderes da República. Pretendem-se investigar as premissas em que estão fundamentadas as ações do Poder Judiciário, resultando no ativismo judicial. Ponderam-se, ainda, os limites do ativismo judicial e a harmonia entre Poderes. Ressaltam-se a importância atual da temática e a necessidade de exploração de suas repercussões para a construção social. A pesquisa, de viés qualitativo e de cunho exploratório, será lastreada em levantamento bibliográfico e dados estatísticos obtidos através de fontes diversas.

PALAVRAS-ChAVE: Conflitos; Políticas Públicas; Poder Judiciário; Ativismo judicial; Direitos Fundamentais.

\section{THE PRECAUTIONARY PRINCIPLE UNDER THE PERSPECTIVE OF THE JUDICIALIZATION OF FUNDAMENTAL RIGHTS: RISKS OF JUDICIAL ACTIVISM TO THE HARMONY BETWEEN THE POWERS.}

\begin{abstract}
This study proposes to analyze the precautionary measures and limits adopted by the Powers of the Republic. We intend to investigate the premises on which the actions of the judiciary are based, resulting in judicial activism. The limits of judicial activism and the harmony between Powers are also considered. The current importance of the theme and the need to explore its repercussions for social construction are highlighted. The research, qualitative bias and exploratory, will be based on bibliographic survey and statistical data obtained from different sources.
\end{abstract}

KEY WORDS: Conflicts; Public Policies; Judiciary; Judicial activism; Fundamental Rights.

\footnotetext{
${ }^{1}$ Mestrando em Direito pela Universidades Unichristus, possui graduação em Direito pela Faculdade Integrada da Grande Fortaleza (2017) ,Pòs Graduação em Aperfeiçoamento de Oficiais pela Academia Edgard Facó PM/Ceará (2005), Bacharel em Segurança Publica pela Academia Edgar Facó - PM/Ceará (1999) , Pós Graduação em Segurança Pública PM /BM pela Academia Edgard Facó - PM/ Ceará (2016) e Especialização em Cidadania, Direitos Humanos e Segurança Pública pela Universidade Federal do Ceará (2011)

${ }^{2}$ Mestre e Doutor em Direito pela PUC-SP. Pós-doutorando em Direito pela Universidade Presbiteriana Mackenzie e pela Universidade de Fortaleza. Professor do programa de pós- graduação em direito da Unichristus. Procurador Federal. Email: andrestudart@hotmail.com.
} 


\section{INTRODUÇÃO}

Vivemos em uma sociedade globalizada exposta, fato inevitável e concreto, a constantes riscos de toda natureza ${ }^{2}$. A complexidade e a pluralidade social, somadas a essa globalização, passaram a exigir do poder público uma maior atenção às suas necessidades.

As novas demandas sociais fazem surgir novos direitos. Nessa complexidade, a busca por inovadoras políticas públicas, expõe o Estado e a sociedade a cruzarem riscos mutuamente. Dentro dessas perspectivas, e para evitar prejuízos de toda monta, o princípio da precaução, como medida de cautela, deve ser um método a ser utilizado que venha a atender às respectivas demandas.

Sob essa perspectiva, passados trinta e um anos da Constituição Democrática de 1988, o Brasil ressente-se ainda em proporcionar efetividade aos direitos e garantias fundamentais nela previstos. Entretanto, apesar dessa carência efetiva, percebe-se que houve diversos avanços e conquistas, objetivando a implementação desse compromisso garantidor.

O Estado tem recorrido a diferentes estruturas sociais e jurídicos para assegurar o cumprimento de políticas públicas que amenizem a situação da população carente desses serviços. Assim, a jurisprudência pátria dos Tribunais Superiores, sobretudo, do Supremo Tribunal Federal, vem sendo utilizada como importante ferramenta de regulamentação e concretização desses direitos, aliados a outros institutos jurídicos.

Em face da ausência de atos normativos do Poder Legislativo e da ineficiência administrativa do Poder Executivo na concessão direitos, a população passa a buscar outras alternativas. Produtos da dinâmica social, esses novos direitos, em determinadas situações, carecem de atendimento imediato. Assim, o acolhimento à efetivação desses direitos previstos como fundamentais é função estatal, que se desrespeitados, viola princípios constitucionais.

Portanto, a forma de Estado Democrático de Direito, adotado pelo Brasil, exige a adoção de uma postura voltada a cumprir sua função frente à sociedade, a qual espera uma atitude proativa do Estado.

Com efeito, a Constituição da República Federativa do Brasil de 1988 apresenta um rol de direitos e garantias, cuja implementação deve ser garantida pela Administração Pública em benefício de seus administrados. Esta mesma Carta Magna apresenta, dentro do elenco de 
responsabilidades estatais, a previsão da separação de seus poderes. Entretanto, tendo em vista as angustias sociais, um desses Poderes vem sobrepondo-se aos demais: o Poder Judiciário ${ }^{3}$.

Nessas perspectivas, para o cumprimento dos preceitos constitucionais não exercido pelos demais poderes, tem o Poder Judiciário desempenhado um papel de protagonismo judicial em suas atribuições. Esse protagonismo tem sido desempenhado na seara da administração para suprir as demandas sociais no exercício de seus direitos.

Infere-se que em face da leniência dos demais Poderes da República, em exercer suas respectivas funções e competências constitucionais, a sociedade tem buscado a resolução de suas demandas no Poder Judiciário. No entanto, apesar de toda a previsão normativa expressa na Constituição e demais leis, o Estado ainda vem exercendo suas funções de forma ineficiente, mesmo sob a batuta das sentenças daquele poder.

Entretanto, há uma angustia dos gestores públicos resultantes da ingerência do Poder Judicial na administração. Tal aflição está nas decisões judiciais que tem implicado seriamente no controle e planejamento da gestão, como também no respectivo orçamento público.

Dessa forma, os Entes da Federação, com as decisões judiciais, estão comprometendo suas despesas para cumprir as sentenças, as quais somente podem ser criadas através de lei ou decisão judicial, indicando a respectiva fonte geradora dos recursos a serem gastos.

Percebe-se, porém, que com essas ações potencializadoras do Poder Judiciário, objetiva-se o exercício do direito à cidadania. Essa expectativa gera a aquisição de novas necessidades que exigem a adoção de tomadas de decisões em respeito ao Estado Democrático de Direito. Tais fatores resultam na judicialização das coisas, fato que está alcançando um ativismo judicial em detrimento dos demais poderes.

Nessa ânsia de contribuir para o exercício da cidadania social, notadamente no cumprimento de direitos fundamentais, o Poder Judiciário tem se destacado. Esse destaque positivo para a sociedade tem resultado em um risco de invasão dos poderes, bem como para a harmonia prevista na Constituição Pátria e o comprometimento da Democracia.

\footnotetext{
${ }^{3}$ Ainda sobre o Judiciário, cabe ressaltar que é uma instância de sobreposição em face dos outros dois Poderes na medida em que lhe é dado rever (no mérito) e anular (em face de vício insanável) os atos e condutas daqueles, assim, controlando-lhes a legalidade, eficiência, moralidade e economicidade (e mesmo a observância de súmula vinculante do SFT, pela Administração Pública: CF/1988paragrafo $3^{\circ}$, do art. 103-A) (MANCUSO, 2015. p. 101).
} 
A pretensão deste artigo é investigar os limites de atuação de cada Poder da República e as questões voltadas a indicar o papel de cada instituição dentro dos limites de suas competências. Ressalta-se, também, a necessidade de compreender a atuação proativa, imbuída de toda precaução do Poder Judiciário na consecução das realizações das demandas sociais surgidas, cuja resolução foi denominada de ativismo judicial.

A justificação para o tema emana de sua importância social democrática, além de

ser um tema atual que tem provocado questionamentos entre operadores do direito e inquietado integrantes dos demais Poderes. Ademais, sua importância para a academia também repercute como de grande importância para o debate científico e acadêmico, objetivando maior qualidade nessas questões e a busca da segurança jurídica nas sentenças prolatadas.

Para a consecução deste objetivo, utilizou-se de pesquisa bibliográfica, de consulta à legislação pertinente, nos sítios da internet, bem como em outras fontes de dissertações e artigos científicos que contribuíram para este estudo. Na metodologia, valeu-se da abordagem hipotético-indutiva, de forma exploratória, com uma avaliação qualitativa da hipótese do tema.

Destarte, propõe-se a apresentação do estudo deste artigo com a introdução do tema por meio de pontos importantes que gravitam em torno da temática, realizando inicialmente sua devida contextualização para dar sequência aos demais tópicos.

No tópico inaugural analisaremos o papel do Estado como provedor social: as medidas de precaução para o cumprimento da função do Estado Democrático de Direito; em seguida, aborda-se, como forma de compreender as nuances das forças que movimentam a administração pública e a nova dinâmica social na perspectiva de agentes de atuação, esclarecendo sobre as Complexidades e Conflitos Sociais por Demanda de Direitos, a Separação dos Poderes; encerrando o último tópico, apresentam-se os motivos, a necessidade e os resultados da intervenção do Judiciário na realização das políticas públicas: uma perspectiva para cumprimento das garantias fundamentais. Por fim, seguem as considerações finais do tema.

\section{O ESTADO COMO PROVEDOR DA SOCIEDADE: AS MEDIDAS DO PRINCÍPIO DE PRECAUÇÃO E OS RISCOS DO DESCUMPRIMENTO DA JURISDIÇÃO ESTATAL}


Desde os registros da história da humanidade, muitos pensadores, desde a Grécia antiga até Roma, procuram encontrar uma definição e saber quais as razões, objetivos e finalidade do Estado. Sob essa perspectiva, somando-se a essas inquirições, a história da filosofia do direito, e mais recentemente a hermenêutica jurídica, tem se deparado com questionamentos sobre o papel do Estado.

Nesse desiderato, a respectiva literatura indica que diferentes juristas levantado questionamentos em debater o papel do Estado, bem como sua função constitucional. Nesse intuito de buscar a razão do Estado, várias versões foram apresentadas, desde a razão conquistadora do inimigo, passando pela conservação política, garantindo a continuidade e a preservação da autoridade estatal para construir e preservar o mercado, mantendo a ordem interna e externa com suas garantias individuais judiciais e cuidando por obras e serviços (BERCOVICI, 2008).

Como resultado de uma convenção, o Estado seria um artificio da inteligência humana voltado a realizar sua tutela social. O Estado moderno é formado por uma sociedade com base territorial e com o exercício de soberania, cujos objetivos são de ordem e defesa social. Sua finalidade se apresenta de forma ampliada para a realização do bem público (AZAMBUJA, 2008).

A sociedade contemporânea, antes compreendida como surgida da economia, agora é inferida como resultante do advento da globalização sistêmica que promove uma transnacionalidade, mitigando e/ou ampliando as liberdades e outros direitos. Aliada a esse fator globalizante, que aproximou e afastou as relações sociais, apresenta-se também a tecnologia que está produzindo uma sociedade liquida (BAUMAN, 2007).

É sabidamente compreendido que o advento da globalização e o avanço tecnológico produzem o desenvolvimento. Contudo, o desenvolvimento produz riscos de toda natureza. Esse desenvolvimento produz uma situação de vulnerabilidade social que impossibilita o acesso aos direitos (BECK, 2010).

Desta forma, o Estado, como um ente provedor de tutela jurisdicional, é constituído por poderes que desempenham suas funções para atender à administração dentro dos respectivos campos de atuação e competência. Sob esse viés, ele tem o mister de garantir direitos para seus administrados como função de alcance do bem-estar social.

Compreende-se que, para o exercício de suas finalidades, o Estado, dentro de sua função teleológica, correlata ao direito, necessita adotar certos procedimentos visando ao 
exercício de suas atribuições (BOBBIO, 1992). Tais procedimentos traduzem-se em medidas de vigilância, objetivando a utilização do princípio da precaução ${ }^{4}$ para minimizar os riscos decorrentes da realização dos direitos fundamentais prescritos na Constituição Federal de 1988.

Sedimentada no Estado Democrático de Direito, a Carta Magna preconiza no artigo $5^{\circ}$, a efetivação dos direitos e garantias fundamentais da pessoa humana. Contudo, apesar da previsão garantista, a Administração Pública tem encontrado óbices para o cumprimento dessas garantias, bem como a realização de seus desideratos de pacificação social.

A ausência de legislação normativa da lavra do Poder Legislativo e de uma administração competente do Poder Executivo não podem paralisar a implementação e o exercício de políticas públicas. Por conseguinte, a falta de atos normativos que regulamentem a concessão de novos direitos surgidos pela dinâmica social, ou o acesso ao cumprimento de direitos fundamentais, é inconcebível que o Estado descumpra seu desiderato constitucional na concessão desses direitos.

Nesse sentido, os fatores que conduzem o Estado a agir aplicando o princípio de precaução estariam na hipótese da ocorrência de riscos na execução dos serviços públicos de forma eficaz. Essa conduta estatal se traduziria em medidas indicadas por aquele princípio em mitigar a ineficiência dos Poderes da República, dentro de suas competências institucionais, os quais estão gerando expectativas sociais negativas (ARGUELHES; LEAL, 2006).

Portanto, para que se evite um caos social, traduzidos na violação de direitos humanitários, resultante do descumprimento e desrespeito aos preceitos da dignidade da pessoa humana, a sociedade tem encontrado no Poder Judiciário um porto seguro para a solução de suas demandas.

Dentro dessa perspectiva, se porventura a população não for atendida em suas necessidades, os riscos para a democracia seriam altamente prejudiciais para a manutenção e preservação do Estado Democrático de Direito.

Destarte, a real precaução está em analisar e reavaliar as competências dos Poderes Executivo, Legislativo e Judiciário, apontando suas carências no exercício de suas atividades e as possibilidades de riscos para a promoção e consolidação dos diretos fundamentais previstos no Estado de Direito (ARGUELHES; LEAL, 2006).

\footnotetext{
${ }^{4}$ Em suas variadas versões e, principalmente, na versão forte, o princípio impõe o ônus da prova àqueles que criam um risco potencial, além de requerer a regulação das atividades em questão, ainda que seja impossível provar o grau de probabilidade de essas atividades produzirem danos significativos (Sunstein, 2013)
} 
Deste modo, para um melhor entendimento deste estudo, demonstrados nos aspectos que orbitam no entorno do exercício dos riscos e precaução para a consecução dos direitos fundamentais, aborda-se as complexidades e os conflitos sociais, bem como a divisão de Poderes da República, será o tema a ser analisado no próximo tópico.

\section{AS COMPLEXIDADES E OS CONFLITOS SOCIAIS POR DEMANDA DE DIREITOS, A SEPARAÇÃO DOS PODERES}

A humanidade em movimento, segundo Bauman (2007), tem produzido uma sociedade descartável. A teleologia é inerente a sociedade e seus anseios regem também o direito (BOBBIO, 1992). As sociedades contemporâneas estão assentadas num dinamismo de complexidade. Ressalte-se que essa singularidade humana, dentro de um conjunto de indivíduos que compõem essa sociedade (DURKHEIM, 2001), provoca uma pluralidade de interesses (BARREIRA, 2010). Consequentemente, vive-se numa sociedade complexa e pluralista onde a demanda por interesses individuais não é alcançada pela normatização legislativa, em face do surgimento de novos fatos sociais (MANCUSO, 2015).

$\mathrm{O}$ advento da pluralidade social que demanda soluções para novos fatos sociais requer do poder jurisdicional a adoção de medidas de forma célere. Essa complexidade pautada na pluralidade faz com que entrem em conflito interesses interpessoais de toda a natureza, inclusive em políticas públicas e, notadamente, as que envolvem direitos fundamentais.

Vivemos em uma sociedade pluralista, onde os anseios por políticas públicas esbarram na inércia dos Poderes Executivo e Legislativo. Definidos como poderes políticos, são representantes da sociedade, cujos integrantes foram conduzidos por meio de uma eleição através do voto (MANCUSO, 2015).

O Poder da Constituição, preconizado em seu artigo em seu Art. $2^{\circ}$, preceitua que: "São Poderes da União, independentes e harmônicos entre si, o Legislativo, o Executivo e o Judiciário.” Essa divisão de poderes indica as respectivas competências, as quais deverão ser exercidas de forma harmônica e independente. 
A fundamentação para o funcionamento e separação desses poderes, com suas respectivas competências, encontram previsão constitucional $1^{5}$ que especifica os limites de atribuições com suas respectivas competências.

Entretanto, em face desse conjunto de fatores de complexidade social, sedimenta-se a imperiosa necessidade de prover à sociedade de seus direitos e garantias previstos na Constituição. $\mathrm{O}$ alcance desses direitos foi delegado pela sociedade a seus representantes, pelo sufrágio do voto. Acontece que a inércia dos Poderes Políticos tem provocado uma orfandade social e isso tem exigido do Poder Judiciário a adoção de medidas saneadoras concedendo tais direitos.

Essa carga de judicialização política recepcionada pelo Poder Judiciário é resultado do surgimento de novas formas de direito (FISCHER, 2014), em que a sociedade não encontra amparo em seus representantes que não agem diante da ausência de normas que solucionem suas demandas.

A tutela jurisdicional de concessão de políticas públicas e concessão de direitos e garantias é uma das formas de pacificação social de responsabilidade do Estado. Nessa configuração, deve o Estado buscar mecanismos que supram suas deficiências. Entretanto, em virtude da ausência de determinadas políticas sociais, estão levando o Estado a promover um desequilíbrio em suas próprias atribuições de competências (BARROSO, 2009).

Este desequilíbrio está na atuação do Poder Judiciário em suprir a deficiência dos demais poderes. A desestabilização na Administração Pública, protagonizada pelo próprio Estado, resulta da inquietação social que, de forma organizada ou não, procura mecanismos próprios de equilíbrio para suas demandas, diretamente, sem a intervenção da mão estatal (MARTINS, 2013). Como expõe Mancuso (2015, p. 94):

Ainda que hoje se possa ter como defasada a (outrora) rígida separação entre os Poderes, não há que negar que a boa gestão da coisa pública e a melhor tutela do interesse geral da coletividade pressupões uma certa flexibilidade e coordenação entre as instâncias do Poder, o que pressupões uma certa distribuição-nem sempre equânime-de tarefas e encargos, com vistas a alcançar a desejável eficiência do desempenho do setor público, estabelecido no art. 37, caput da CF/1988 dentre as

\footnotetext{
${ }^{5}$ Título IV, Da Organização dos Poderes Capítulo I - Do Poder Legislativo Seção I - Do Congresso Nacional Art. 44. O Poder Legislativo é exercido pelo Congresso Nacional, que se compõe da Câmara dos Deputados e do Senado Federal. Capítulo II - Do Poder Executivo Seção I - Do Presidente e do Vice-Presidente da República Art. 76. O Poder Executivo é exercido pelo Presidente da República, auxiliado pelos Ministros de Estado. Capítulo III - Do Poder Judiciário Seção I - Disposições Gerais, Art. 92. São órgãos do Poder Judiciário: (EC no 45/2004 e EC no 92/2016) (CRFB/1988).
} 
metas a que se preordena a Administração Pública, em seu sentido largo (e não apenas o Poder Executivo).

Entretanto, a atuação do Poder Judiciário não se faz de forma gratuita, violadora ou usurpadora dos demais Poderes. Encontra fundamento legal para agir sobrepondo-se aos demais. Essa legitimidade de agir está prevista no inciso XXXV do artigo $5^{\circ}$ da Constituição Federal, que apresenta a regra do Princípio da Inafastabilidade da Jurisdição, ao enunciar que: "a lei não excluirá da apreciação do Poder Judiciário lesão ou ameaça a direito" (ROCHA, 2017).

Consequentemente, os anseios sociais são fortemente agravados com a ausência de políticas públicas. Essa lacuna surgida resulta na violação de direitos da cidadania e da dignidade da pessoa humana, aliada à inércia do Poder Público. Daí a imperiosa necessidade de que se busque solucionar essas questões com medidas alternativas.

Por um viés positivo, existe uma percepção da inserção no ordenamento jurídico brasileiro das modernas correntes jurídicas que compõem um verdadeiro sincretismo metodológico (SILVA, 2005), voltados a aplicação das normas e princípios.

Apresentam-se assim para compreender de forma diligente o mecanismo estatal de funcionamento jurídico-administrativo. Constatam-se a distribuição de competências e as capacidades das instituições encarregadas de gerirem as atividades visando à realização de suas respectivas atribuições dentro de seus limites de atuação (ARGUELHES; LEAL, 2006).

A sociedade contemporânea organizada pugna por seus direitos sob a orientação globalizada da informação e da tecnologia, estruturando-se sob a égide da complexidade. Como produtora de fatos sociais, ela exige do direito uma normatização para o surgimento de novas situações sobre as quais a norma vigente não mais atende. Essa maneira de a sociedade se reestruturar remonta a ideia da teoria autopoiética do Direito ${ }^{6}$ (TEUBNER, 1989), apresentada inicialmente na obra Árvore do Conhecimento (MATURANA; VARELA, 1995).

\footnotetext{
${ }^{6}$ Origem da palavra "AUTOPOIESE": deriva do grego "autos" (por si próprio) e "poiesis" (criação própria, produção, origem). O direito auto se completa, auto se regula; O termo "Autopoiese" foi criado na década de 70 pelos biólogos chilenos Humberto Maturana e Francisco Varela, em forma de uma concepção biológica que tenta explicar o fenômeno da vida, ou seja, a Teoria Autopoiética, que tem como ideia básica um sistema organizado, fechado e auto-suficiente; No início da década de 80, através do sociólogo alemão Nicklas Luhmann, o conceito de autopoiese é introduzido nas ciências sociais, porém de forma diferenciada. Depois foi levada para as ciências jurídicas e criada a Teoria Autopoiética do Direito; CARACTERÍSTICAS DA TEORIA AUTOPOÉTICA DO DIREITO: A- A sociedade exerce influência indireta sobre o direito, ou seja, o sistema jurídico pode assimilar os fatores do meio ambiente de acordo com seus próprios critérios (através da cognição); B- A autopoiese exige para o ordenamento jurídico um sistema dotado de fechamento auto-referencial, isto é, a própria normatividade para o sistema jurídico; C- Em face da influência indireta da sociedade, o direito
} 
Para Martins (2013), a sociedade moderna, que organizou espontaneamente a estabilidade sócionormativa, - isto é, que foi encontrando maneiras de prover suas expectativas -, parece hoje entregar-se à tarefa de reinvenção dessa estabilidade. Sob essa expectativa, a sociedade se ressente de meios políticos-públicos para a solução de suas angustias e amarguras pautadas na aquisição de seus direitos. Essa expectativa por direitos conduz a sociedade à autonormatização e à reconstrução de seu equilíbrio.

Destarte, o dinamismo social, com a globalização e os avanços tecnológicos, produziu uma nova feição social de positivista do poder (HAN, 2017). Nessa nova concepção da sociedade não há espaço para o conformismo, e a disposição em buscar seus direitos é fator essencial para a realização do desenvolvimento. Consequentemente, para o mesmo autor, a sociedade do século XXI não é mais a sociedade disciplinar, mas uma sociedade de desempenho. Também seus habitantes não se chamam mais "sujeitos de obediência", mas sujeitos de desempenho e produção.

Portanto, no cenário internacional, e especificamente no cenário brasileiro de concretização do direito, a sociedade contemporânea caminha com a finalidade de conquistar a promoção e efetivação dos direitos fundamentais, em face da atuação Jurídica (BARROSO, 2009); isto é, uma judicialização das coisas (DURKHEIM, 2001), com a permissividade constitucional. Ressalta-se, entretanto, que mencionada conduta para o alcance dessas garantias está provocando um ativismo judicial. Esta judicialização está potencializando as ações do Poder Judiciário e o colocando em um patamar de protagonista de concessão de Direito Fundamentais. Observa-se que é esse fato que vem causando desequilíbrio entre os Poderes e o incremento do chamado ativismo judicial, cuja análise será o próximo tópico.

\section{A INTERVENÇÃO DO JUDICIÁRIO COMO ATIVISMO JUDICIAL: UMA PERSPECTIVA PARA O CUMPRIMENTO DAS GARANTIAS FUNDAMENTAIS}

O advento da redemocratização, alcançado pela promulgação da Constituição da República Federativa do Brasil de 1988 (CRFB/88), foi o divisor de águas para consagração do Estado Democrático de Direito.

seleciona o que dela provém e interessa ao ordenamento jurídico; D- O direito é, portanto, um sistema normativamente fechado, que serve à autopoiese, mas cognitivamente aberto, na medida em que permite a concordância do processo com o meio ambiente; E- Abertura cognitiva adequada ao meio ambiente (externo) e capacidade de conexão da reprodução normativa autopoiética (interno). 
Com a adoção do regime democrático e da forma de Estado de Direito, o Brasil, na condução de sua Administração Pública, passou a necessitar de mecanismos de pacificação social. Essa busca pelo bem-estar social, pressupõe a existência de um instrumental jurídico que contemple direitos e deveres para o fiel cumprimento de seus fundamentos e objetivos explícitos.

Nesse diapasão, contemporaneamente com a sociedade civilizada, por meios de informações globalizadas e tecnologicamente interligada, propiciou-se uma complexidade e pluralidade de indivíduos no contexto social. Esse resultado civilizatório multicultural ou transnacional proporcionou um cenário de independência e liberdade, tanto na esfera individual como na esfera coletiva, frente a ações públicas que resultam numa luta por novas formas de direito e produzem algum desenvolvimento pessoal (SEN, 2010).

Nesse viés de conquistas por direitos para o desenvolvimento pessoal e social, mais um componente tem contribuído para o alcance de mais conquistas no campo social, que é a sociedade organizada tecnologicamente em rede. Conforme Castells (2005, p. 23):

\begin{abstract}
A sociedade em rede é uma sociedade hipersocial, não uma sociedade de isolamento. As pessoas, na sua maioria, não disfarçam a sua identidade na Internet, excepto alguns adolescentes a fazer experiências de vida. As pessoas integraram as tecnologias nas suas vidas, ligando a realidade virtual com a virtualidade real, vivendo em várias formas tecnológicas de comunicação, articulando-as conforme as suas necessidades. Contudo, existe uma enorme mudança na sociabilidade, que não é uma consequência da Internet ou das novas tecnologias de comunicação, mas uma mudança que é totalmente suportada pela lógica própria das redes de comunicação. É a emergência do individualismo em rede (enquanto a estrutura social e a evolução histórica induz a emergência do individualismo como cultura dominante das nossas sociedades) e as novas tecnologias de comunicação adaptam-se perfeitamente na forma de construir sociabilidades em redes de comunicação auto-selectivas, ligadas ou desligadas dependendo das necessidades ou disposições de cada indivíduo. Então, a sociedade em rede é a sociedade de indivíduos em rede.
\end{abstract}

Invocando essa perspectiva por garantias e direitos, a sociedade se reorganiza e procura no Poder Judiciário amparo para a solução de suas demandas. A fundamentação que habilita esse Poder a realizar atividades que excedem suas competências encontra amparo no artigo $5^{\circ}$ inciso $\mathrm{XXXV}, \mathrm{CRFB} / 88$, como anteriormente mencionado.

Ademais, concorda-se que todos os Poderes dispõem de legitimidade constitucional para contribuir para o desenvolvimento Nacional. E, em face desse vácuo deixado pelos demais Poderes, o Poder Judiciário tem chamado para si a responsabilidade de concretização dos objetivos e fundamentos da República Federativa do Brasil, como forma de contribuir 
para edificar uma sociedade justa, livre e solidária; atuando para a concretização do Estado Democrático (MANCUSO, 2015).

Portanto, ao invocar o exercício de competências alheias a sua, o Poder Judiciário procura apenas fazer caminhar a administração de políticas públicas. Mormente, tal gestão carece de decisão para atender questões sociais, as quais têm prioridade de tramitação, artigo $5^{\circ}, \mathrm{CRFB} / 88$, entre as demais.

\begin{abstract}
LXXVIII - a todos, no âmbito judicial e administrativo, são assegurados a razoável duração do processo e os meios que garantam a celeridade de sua tramitação. § 10 As normas definidoras dos direitos e garantias fundamentais têm aplicação imediata. $\S 20$ Os direitos e garantias expressos nesta Constituição não excluem outros decorrentes do regime e dos princípios por ela adotados, ou dos tratados internacionais em que a República Federativa do Brasil seja parte. § 3o Os tratados e convenções internacionais sobre direitos humanos que forem aprovados, em cada Casa do Congresso Nacional, em dois turnos, por três quintos dos votos dos respectivos membros, serão equivalentes às emendas constitucionais. $1 \S 4 \mathrm{o} O$ Brasil se submete à jurisdição de Tribunal Penal Internacional a cuja criação tenha manifestado adesão.(CRFB/88)
\end{abstract}

Nesse passo, as decisões que avançam nas competências de outro órgão da Administração Pública por sua judicialização popular, e que dá ensejo ao termo conhecido como ativismo jurídico (MARMELSTEIN, 2018), são questões de saúde pública, que envolvem pedido de liminar para a concessão de medicamento. Portanto, a concessão é um direito fundamental negado pelo órgão responsável (ZAVASCKY, 2008).

Com efeito, as respectivas decisões do Judiciário em desfavor da administração pública, têm provocado um desequilíbrio orçamentário nos Entes Federativos, bem como na concessão de politicas pública, notadamente na área de saúde, comprometendo significativamente o atendimento à coletividade.

No que diz respeito à judicialização e ao ativismo judicial, Barroso (2008) esclarece que ambos pertencem à mesma família, porém são de origens diferentes. Para ele, a judicialização é uma circunstância resultante do modelo constitucional adotado, e não de uma questão política. Sobre a questão, plausível é a cita do autor (2009. p. 06):

A ideia de ativismo judicial está associada a uma participação mais ampla e intensa do Judiciário na concretização dos valores e fins constitucionais, com maior interferência no espaço de atuação dos outros dois Poderes. A postura ativista se manifesta por meio de diferentes condutas, que incluem: (i) a aplicação direta da Constituição a situações não expressamente contempladas em seu texto e independentemente de manifestação do legislador ordinário; (ii) a declaração de inconstitucionalidade de atos normativos emanados do legislador, com base em critérios menos rígidos que os de patente e ostensiva violação da Constituição; (iii) a 
imposição de condutas ou de abstenções ao Poder Público, notadamente em matéria de políticas públicas.

Percebe-se, assim, que a tutela jurisdicional se apropria de um amplo raio de ação que se norteia na assistência, no amparo, na defesa e na vigilância que o Estado, por seus órgãos jurisdicionais, presta aos direitos dos indivíduos. Assim, ao prestar a tutela, o Estado está analisando a existência do direito reclamado, suas violações, impondo as medidas para sua manutenção ou reparação (ZAVASCKY, 2008).

Na busca de efetivação dos direitos fundamentais, compreende-se que a atividade do Poder Judiciário tem grande relevância no exercício de ações voltadas ao cumprimento dos objetivos e fundamentos da Constituição. Trata-se do ativismo judicial. Entretanto, para Mancuso (2015, p. 92), essa atuação está legalmente prevista e não se traduz numa invasão de competência. Vejamos:

Que não se trata de uma ingerência direta e espontânea do Judiciário, e sim da participação do povo - em cujo nome o poder é exercido - no controle boa gestão da coisa pública, através dos instrumentos processuais, que estes sim, induzem a intervenção judicial.

Partindo do pressuposto da manutenção ou reparação da dignidade humana (BARROSO, 2009, p. 338), o ativismo judicial funciona como um mecanismo indispensável para a realização de políticas públicas. Sua aplicação preocupa-se precipuamente em direcionar e concretizar as respectivas garantias prescritas nos "Princípios Constitucionais", os quais estão em sintonia com os tratados de direitos humanos dos quais o Brasil é signatário.

Entretanto, o que se tem observado é uma inquietação dos operadores do direito e dos integrantes dos demais Poderes da República. Em resposta, Luiz Roberto Barroso (2009, p. 19) pondera que o ativismo judicial, apesar de ainda poder ser considerado parte da solução, não pode ser utilizado de maneira excessiva. Vejamos:

O ativismo judicial, até aqui, tem sido parte da solução, e não do problema. Mas ele é um antibiótico poderoso, cujo uso deve ser eventual e controlado. Em dose excessiva, há risco de se morrer da cura. A expansão do Judiciário não deve desviar a atenção da real disfunção que aflige a democracia brasileira: a crise de representatividade, legitimidade e funcionalidade do Poder Legislativo. Precisamos de reforma política. E essa não pode ser feita por juízes. 
Outros aspectos que fundam da judicialização, diz respeito à necessidade de ponderar as consequências dessas decisões. Nesse sentido, é importante observar que recentemente a Lei $\mathrm{n}^{\mathrm{o}}$ 13.655/18, alterou a Lei de Introdução as Normas do Direito Brasileiro (LINDB) e passou a impor a análise consequencialista das decisões proferidas no âmbito judicial em desfavor da administração pública.

Art. 20 . Nas esferas administrativa, controladora e judicial, não se decidirá com base em valores jurídicos abstratos sem que sejam consideradas as consequências práticas da decisão. Art. 22. Na interpretação de normas sobre gestão pública, serão considerados os obstáculos e as dificuldades reais do gestor e as exigências das políticas públicas a seu cargo, sem prejuízo dos direitos dos administrados.

Com efeito, seria absolutamente incoerente, absurdo, por exemplo, uma decisão judicial exigindo do gestor a concessão de leito especial ou vaga em Unidade de Tratamento Intensivo (UTI) para atender uma pessoa. De que forma o administrador deveria cumprir a respectiva sentença judicial? Como cumprir esse dever de forma imediata. Ele deveria retirar uma pessoa que já estivesse em tratamento para atender a determinação judicial?

Infere-se, portanto, que a judicialização e o ativismo judicial são importantes mecanismos viabilizadores de direitos fundamentais. O primeiro (judicialização) consiste na atuação direta do cidadão perante o Judiciário na perseguição de um pretenso direito subjetivamente seu; o segundo, o ativismo judicial, que se apresenta como solução para as demandas sociais as quais não estão sendo atendidas pela abstenção dos demais poderes. Nessa visão, compreende-se que esses dois institutos são de necessidade imperativa para o desiderato do Estado Democrático de Direito, devendo, no entanto, medir suas consequências para a coletividade.

Deste modo, para que haja a tão prevista harmonia entres os Poderes da República e para que a democracia não corra o risco de se exaurir, a intervenção do Poder Judiciário em questões alheias a sua competência deve ser pacificadora, casual, passageira e miradas em suas consequências. Ademais, devem o Poder Executivo e Poder Legislativo buscar resgatar suas credibilidades e realizar uma restruturação, com o intuito de executar de maneira eficiente as suas competências constitucionais. 


\section{CONSIDERAÇÕES FINAIS}

O advento da globalização e as conquistas tecnológicas resultantes dessa internacionalização de informações têm o condão de aproximar e, ao mesmo tempo, afastar as pessoas. Nesse contexto, cria-se uma comunidade multicultural, a qual, por meio das redes sociais de conexão, trocam informações e disseminam conhecimentos.

A sociedade contemporânea tem uma composição bastante complexa, resultante do advento da globalização que tem produzido o avanço tecnológico em diversas áreas e contribuído para uma melhor qualidade de vida das pessoas Este fator também tem proporcionado um grau de desenvolvimento aos Estados-nações que procuram interligar-se através de tratados e outros documentos internacionais.

Após a Segunda Guerra Mundial, os Estados do ocidente passaram a tutelar de modo mais direto a pessoas humanas. Com isso, as Constituições Nacionais procuraram se adequar a essa nova tendência mundial e adotaram o Estado Democrático de Direito.

No Brasil, com o advento da redemocratização ocorrida após a promulgação da Constituição da República de 1988, conquistou-se o Estado de Direito. Nesse sentido, o compromisso com os objetivos e fundamentos da República garante o acesso a direitos e garantias sob a égide dos princípios dos direitos fundamentais nela previstos.

Dentre as diversas previsões mandamentais envolvendo a Administração Pública está o princípio da separação do Poderes, com a indicação das competências e dos limites de atuação de cada um deles. Obviamente, o necessário desempenho positivo das competências de cada um dos Poderes seguramente repercute no alcance da paz social.

Entretanto, os riscos de direção que permeiam as atividades desses Poderes e a gestão pública dependem de decisões que utilizem o princípio da precaução, objetivando minimizar os danos que porventura advenham da imprecisão na prestação de políticas públicas.

Dentro da perspectiva da globalização e do desenvolvimento pessoal e estatal, entre outros fatores do dinamismo social produtor do direito, resultou-se a complexidade social. Resultante da pluralidade de indivíduos, essa complexidade tem produzido consciente ou inconscientemente uma busca por uma reestruturação normativa.

Esse mecanismo de reorganização ou reestruturação social normativa advém do surgimento e exigências por novas formas de direitos, os quais ainda não encontram previsão. Nessa expectativa de alcance de direitos e garantias, e especificamente os direitos 
fundamentais, a sociedade tem encontrado obstáculos para a aquisição e gozo desse benefício. Os óbices estão na falta de interesse e inércia dos respectivos Poderes Políticos, Legislativo e Executivo.

Entretanto, o que se assiste é a inércia do Poder Legislativo e do Poder Executivo em desempenhar suas atividades de forma efetiva. Esse fato tem produzido insatisfação da população, que de forma ativa tem procurado o exercício de seus direitos.

Em contraposição às expectativas da sociedade, esses dois poderes não têm correspondido às demandas sociais ao exercer suas atividades e competências. A ausência de normas que regulem a aquisição de novos direitos, ou que preencham o vácuo por sua inexistência e a imperiosa efetivação de direitos fundamentais, tem exigido dos dois poderes políticos a tomada de decisões para sanar tais questões.

Portanto, essa leniência tem compelido a sociedade a procurar a realização de seus direitos diretamente no Poder Judiciário. Dessa forma, esse poder tem avocado as responsabilidades dos demais, e solucionado através das respectivas decisões tais demandas. Essa atitude tem provocado uma judicialização social. Essa forma de resolução de conflitos sociais, e em especial a realização dos direitos fundamentais, tem produzido um fato chamado de ativismo judicial, o qual é produto dessa judicialização.

Percebe-se que o cumprimento dos objetivos e fundamentos da República compete aos três poderes. Entretanto, o Judiciário tem se destacado e protagonizado, em face de sua atuação proativa. Destarte, os direitos fundamentais, via de regra, estão sendo objeto de decisões concedidas pela interferência do Poder Judiciário.

Portanto, para que se evite um caos no descumprimento de políticas públicas sociais e a violação de direitos fundamentais da dignidade humana, o Poder Judiciário deve atuar através da judicialização e ativismo judicial.

Entretanto, deve o Judiciário posicionar-se em cumprir os mandamentos constitucionais de forma transitória e pontual para que se evite a ruptura na segurança jurídica e na estabilidade da democracia. Nessa perspectiva, devem o Poder Legislativo e Executivo buscarem mecanismos para reestruturarem-se, para assim concretizarem-se efetivamente no exercício de suas competências resgatando suas credibilidades e a constância democrática do Estado Democrático do Direito, traduzidos na efetivação dos direitos fundamentais da pessoa humana. 


\section{REFERÊNCIAS}

ARGUELHES, Diego Werneck; LEAL, Fernando. O argumento das "capacidades institucionais" entre a banalidade, a redundância e o absurdo. Revista de Direito, Estado e Sociedade, Rio de Janeiro, v. 1, n. 38, p.06-50, jun. 2006.

BARREIRA, César. (ORG). Violência e Conflitos Sociais: Trajetória de Pesquisa. Campinas, SP: Pontes Editores, 2010.

BARROSO, Luis Roberto. Interpretação e aplicação da Constituição: Fundamentos de uma Dogmática Constitucional Transformadora. 7.ed. São Paulo: Saraiva, 2009.

BARROSO, Luís Roberto. Judicialização, ativismo judicial e legitimidade democrática. 2008. Disponível em:

https://www.direitofranca.br/direitonovo/FKCEimagens/file/ArtigoBarroso_para_Selecao.pdf. Acesso em: 08 jun. 2019.

BAUMAN, Zigmunt. Tempos Líquidos. Tradução Carlos Alberto Medeiros. Rio de Janeiro: Jorge Zahar, 2007.

BECK, Ulrich. Sociedade de risco: rumo a uma outra modernidade. Tradução de Sebastião Nascimento; ed. 34, São Paulo. 2010.

BERCOVICI, Gilberto. Soberania e Constituição: Para uma crítica do Constitucionalismo. São Paulo: Quartier Latin, 2008.

BOBBIO, Norberto, A era dos Direitos. Tradução de Carlos Nelson Coutinho. Rio de Janeiro: Campus, 1992.

BRASIL. Constituição (1988). Constituição da República Federativa do Brasil. Brasília, Disponível em:

https://www.planalto.gov.br/ccivil_03/constituicao/constituicaocompilado.html. Acesso em: 22 de maio 2019.

CASTELlS, Manuel; CARDOSO, Gustavo (Orgs.). A Sociedade em Rede: do conhecimento à ação política. Belém (Por) : Imprensa Nacional, 2005

DURKHEIM, Émile. As regras do método sociológico. São Paulo: Editora Martin Claret Ltda, 2001.

FISCHER, Douglas. O Direito Penal na Sociedade de Riscos. Revista do Ministério Público do Rs, Porto Alegre, v. 75, n. 1, p.51-63, 2014

HAN, Byung-Chul. Sociedade do Cansaço. 2 ed. Petropolis, RJ: Vozes, 2017.

LINDB, Lei de Introdução as Normas do Direito Brasileiro . LEI No 13.655, DE 25 DE

ABRIL DE 2018. Disponível em : http://www.planalto.gov.br/ccivil_03/_ato2015-

2018/2017/lei/L13566.htm . Acesso em: 15 de ago. 2019.

Revista Brasileira de Filosofia do Direito | e-ISSN: 2526-012X | Belém | v. 5 | n. 2 | p. 176 - 193 | Jul/Dez. 2019. 
MANCUSO, Rodolfo de Camargo. Acesso à Justiça : Condicionantes legítimas e

Ilegítimas. 2. ed. São Paulo: Revista dos Tribunais, 2015.

MARMELSTEIN, George. O direito fora da caixa.1ed. Salvador: Editora JusPodvim, 2008.

MARTINS, Rui Cunha. O ponto cego do direito. 3.ed. São Paulo: Atlas, 2013.

MATURANA, Humberto; VARELA, Francisco. A árvore do conhecimento: As bases biológicas do entendimento humano. Campinas: Workshopsy - Livraria, Editora e Promotora de Eventos, 1995. Disponível em:

http://materiadeapoioaotcc.pbworks.com/f/Arvore+do+Conhecimento+Maturana+e+Varela.p df. Acesso em: 20 ago. 2019.

ROCHA, Sergio André. Da Lei à Decisão: a segurança Jurídica Tributária Possível na Pós-Modernidade. 1ed. Rio de Janeiro: Editora Lumen Juris. 2017.

SEN, Amartya. Desenvolvimento como liberdade. São Paulo. Companhia das Letras, 2010.

TEUBNER, Gunther. O Direito como sistema autopoiético. Lisboa: Fundação Calouste Gulbenkian, 1989.

ZAWASCKY, Teori albino. Antecipação da tutela. 6. ed. São Paulo: Saraiva, 2008. 